\title{
Strong convergence theorems by Halpern-Mann iterations for multi-valued relatively nonexpansive mappings in Banach spaces with applications
}

\author{
Jin-hua Zhu', Shih-sen Chang ${ }^{2^{*}}$ and Min Liu'
}

\footnotetext{
* Correspondence: changss@yahoo. cn

${ }^{2}$ College of Statistics and Mathematics, Yunnan University of Finance and Economics, Kunming, Yunnan 650221, China

Full list of author information is available at the end of the article
}

\begin{abstract}
In this article, an iterative sequence for relatively nonexpansive multi-valued mapping by modifying Halpern and Mann's iterations is introduced, and then some strong convergence theorems are proved. At the end of the article some applications are given also.
\end{abstract}

AMS Subject Classification: 47H09; 47H10; 49J25.

Keywords: multi-valued mapping, relatively nonexpansive, fixed point, iterative sequence

\section{Introduction}

Throughout this article, we denote by $\mathbb{N}$ and $\mathbb{R}$ the sets of positive integers and real numbers, respectively. Let $D$ be a nonempty closed subset of a real Banach space $E$. A single-valued mapping $T: D \rightarrow D$ is called nonexpansive if $\|T x-T y\| \leq\|x-y\|$ for all $x, y \in D$. Let $N(D)$ and $C B(D)$ denote the family of nonempty subsets and nonempty closed bounded subsets of $D$, respectively. The Hausdorff metric on $C B(D)$ is defined by

$$
H\left(A_{1}, A_{2}\right)=\max \left\{\sup _{x \in A_{1}} d\left(x, A_{2}\right), \sup _{y \in A_{2}} d\left(y, A_{1}\right)\right\},
$$

for $A_{1}, A_{2} \in C B(D)$, where $d\left(x, A_{1}\right)=\inf \left\{\|x-y\|, y \in A_{1}\right\}$. The multi-valued mapping $T: D \rightarrow C B(D)$ is called nonexpansive if $H(T(x), T(y)) \leq\|x-y\|$ for all $x, y \in D$. An element $p \in D$ is called a fixed point of $T: D \rightarrow N(D)$ if $p \in T(p)$. The set of fixed points of $T$ is represented by $F(T)$.

Let $E$ be a real Banach space with dual $E^{*}$. We denote by $J$ the normalized duality mapping from $E$ to $2^{E^{*}}$ defined by

$$
J(x)=\left\{x^{*} \in E^{*}:\left\langle x, x^{*}\right\rangle=\|x\|^{2}=\left\|x^{*}\right\|^{2}\right\}, x \in E .
$$

where $\langle\cdot, \cdot\rangle$ denotes the generalized duality pairing.

A Banach space $E$ is said to be strictly convex if $\frac{\|x+y\|}{2}<1$ for all $x, y \in U=\{z \in E$ : $\|z\|=1\}$ with $x \neq y$. $E$ is said to be uniformly convex if, for each $\epsilon \in(0,2]$, there exists $\delta>0$ such that $\frac{\|x+y\|}{2}<1-\delta$ for all $x, y \in U$ with $\|x-y\| \geq \epsilon$. E is said to be smooth if 
the limit

$$
\lim _{t \rightarrow 0} \frac{\|x+t y\|-\|x\|}{t}
$$

exists for all $x, y \in U$. $E$ is said to be uniformly smooth if the above limit exists uniformly in $x, y \in U$.

Remark 1.1. The following basic properties for Banach space $E$ and for the normalized duality mapping $J$ can be found in Cioranescu [1].

(i) If $E$ is an arbitrary Banach space, then $J$ is monotone and bounded;

(ii) If $E$ is a strictly convex Banach space, then $J$ is strictly monotone;

(iii) If $E$ is a smooth Banach space, then $J$ is single-valued, and hemi-continuous, i.

e., $J$ is continuous from the strong topology of $E$ to the weak star topology of $E^{*}$;

(iv) If $E$ is a uniformly smooth Banach space, then $J$ is uniformly continuous on each bounded subset of $E$;

(v) If $E$ is a reflexive and strictly convex Banach space with a strictly convex dual $E^{*}$ and $J^{*}: E^{*} \rightarrow E$ is the normalized duality mapping in $E^{*}$, then $J^{-1}=J^{*}, J J^{*}=I_{E^{*}}$, and $J^{*} J$ $=I_{E}$;

(vi) If $E$ is a smooth, strictly convex, and reflexive Banach space, then the normalized duality mapping $J$ is single-valued, one-to-one and onto;

(vii) A Banach space $E$ is uniformly smooth if and only if $E^{*}$ is uniformly convex. If $E$ is uniformly smooth, then it is smooth and reflexive.

Next we assume that $E$ is a smooth, strictly convex, and reflexive Banach space and $C$ is a nonempty closed convex subset of $E$. In the sequel, we always use $\varphi: E \times E \rightarrow$ $\mathbb{R}^{+}$to denote the Lyapunov functional defined by

$$
\phi(x, y)=\|x\|^{2}-2\langle x, y y\rangle+\|y\|^{2}, \forall x, y \in E .
$$

It is obvious from the definition of $\varphi$ that

$$
\begin{aligned}
& (\|x\|-\|y\|)^{2} \leq \phi(x, y) \leq(\|x\|-\|y\|)^{2}, \forall x, y \in E . \\
& \phi\left(x, J^{-1}(\lambda J y+(1-\lambda) J z) \leq \lambda \phi(x, y)+(1-\lambda) \phi(x, z)\right),
\end{aligned}
$$

for all $\lambda \in[0,1]$ and $x, y, z \in E$.

Following Alber [2], the generalized projection $\Pi_{C}: E \rightarrow C$ is defined by

$$
\prod_{C}(x)=\arg \inf _{y \in C} \phi(y, x), \forall x \in E .
$$

Let $D$ be a nonempty subset of a smooth Banach space. A mapping $T: D \rightarrow E$ is relatively expansive [3-5], if the following properties are satisfied:

(R1) $F(T) \neq \emptyset$;

(R2) $\varphi(p, T x) \leq \varphi(p, x)$ for all $p \in F(T)$ and $x \in D$;

(R3) $I-T$ is demi-closed at zero, that is, whenever a sequence $\left\{x_{n}\right\}$ in $D$ converges weakly to $p$ and $\left\{x_{n}-T x_{n}\right\}$ converges strongly to 0 , it follows that $p \in F(T)$.

If $T$ satisfies (R1) and (R2), then $T$ is called quasi- $\varphi$-nonexpansive [6]. 
Recently, Nilsrakoo and Saejung [7] introduced the following iterative sequence for finding a fixed point of relatively nonexpansive mapping $T: D \rightarrow E$. Given $x_{1} \in D$,

$$
x_{n+1}=\prod_{D} J^{-1}\left(\alpha_{n} J u+\left(1-\alpha_{n}\right)\left(\beta_{n} J x_{n}+\left(1-\beta_{n}\right) J T x_{n}\right)\right)
$$

where $D$ is nonempty closed convex subset of a uniformly convex and uniformly smooth Banach space $E, \Pi_{D}$ is the generalized projection of $E$ onto $D$ and $\left\{\alpha_{n}\right\}$ and $\left\{\beta_{n}\right\}$ are two sequences in $[0,1]$.

They proved strong convergence theorems in uniformly convex and uniformly smooth Banach space $E$.

Iterative methods for approximating fixed points of multi-valued mappings in Banach spaces have been studied by some authors, see for instance [8-15].

Let $D$ be a nonempty closed convex subset of a smooth Banach space $E$. We define a relatively nonexpansive multi-valued mapping as follows.

Definition 1.2. A multi-valued mapping $T: D \rightarrow N(D)$ is called relatively nonexpansive, if the following conditions are satisfied:

(S1) $F(T) \neq \varnothing$

(S2) $\varphi(p, z) \leq \varphi(p, x), \forall x \in D, z \in T(x), p \in F(T)$;

(S3) $I-T$ is demi-closed at zero, that is, whenever a sequence $\left\{x_{n}\right\}$ in $D$ which weakly to $p$ and $\lim _{n \rightarrow \infty} d\left(x_{n}, T\left(x_{n}\right)\right)=0$, it follows that $p \in F(T)$.

If $T$ satisfies (S1) and (S2), then multi-valued mapping $T$ is called quasi- $\varphi$ nonexpansive.

In this article, inspired by Nilsrakoo and Saejung [7], we introduce the following iterative sequence for finding a fixed point of relatively nonexpansive multi-valued mapping $T: D \rightarrow N(D)$. Given $u \in E, x_{i} \in D$,

$$
x_{n+1}=\prod_{D} J^{-1}\left(\alpha_{n} J u+\left(1-\alpha_{n}\right)\left(\beta_{n} J x_{n}+\left(1-\beta_{n}\right) J w_{n}\right)\right.
$$

where $w_{n} \in T x_{n}$ for all $n \in \mathbb{N}, D$ is a nonempty closed convex subset of a uniformly convex and uniformly smooth Banach space $E, \Pi_{D}$ is the generalized projection of $E$ onto $D$ and $\left\{\alpha_{n}\right\},\left\{\beta_{n}\right\}$ are sequences in $[0,1]$. We proved the strong convergence theorems in uniformly convex and uniformly smooth Banach space $E$.

\section{Preliminaries}

In the sequel, we denote the strong convergence and weak convergence of the sequence $\left\{x_{n}\right\}$ by $x_{n} \rightarrow x$ and $x_{n} \rightarrow x$, respectively.

First, we recall some conclusions.

Lemma 2.1 [16,17]. Let $E$ be a smooth, strictly convex, and reflexive Banach space and $C$ be a nonempty closed convex subset of $E$. Then the following conclusions hold:

(a) $\varphi\left(x, \Pi_{C} y\right)+\varphi\left(\Pi_{C} y, y\right) \leq \varphi(x, y)$ for all $x \in C$ and $y \in E$;

(b) If $x \in E$ and $z \in C$, then

$$
z=\prod_{C} x \Leftrightarrow\langle z-y, J x-J z\rangle \geq 0, \forall y \in C ;
$$


(c) For $x, y \in E, \varphi(x, y)=0$ if and only $x=y$.

Remark 2.2. If $E$ is a real Hilbert space $H$, then $\varphi(x, y)=\|x-y\|^{2}$ and $\Pi_{C}$ is the metric projection $P_{C}$ of $H$ onto $C$.

Lemma 2.3 [18]. Let $E$ be a uniformly convex Banach space, $r>0$ be a positive number and $B_{r}(0)$ be a closed ball of $E$. Then, for any given sequence $\left\{x_{i}\right\}_{i=1}^{\infty} \subset B_{r}(0)$ and for any given sequence $\left\{\lambda_{i}\right\}_{i=1}^{\infty}$ of positive numbers with $\sum_{i=1}^{\infty} \lambda_{i}=1$, then there exists a continuous, strictly increasing, and convex function $g:[0,2 r) \rightarrow[0, \infty)$ with $g$ $(0)=0$ such that for any positive integers $i, j$ with $i<j$,

$$
\left\|\sum_{n=1}^{\infty} \lambda_{n} x_{n}\right\|^{2} \leq \sum_{n=1}^{\infty} \lambda_{n}\left\|x_{n}\right\|^{2}-\lambda_{i} \lambda_{j} g\left(\left\|x_{i}-x_{j}\right\|\right)
$$

In what follows, we need the following lemmas for proof of our main results.

Lemma 2.4 [17]. Let $E$ be a uniformly convex and smooth Banach space and let $\left\{x_{n}\right\}$ and $\left\{y_{n}\right\}$ be two sequences of $E$ such that $\left\{x_{n}\right\}$ or $\left\{y_{n}\right\}$ is bounded. $\operatorname{If}_{n \rightarrow \infty} \varphi\left(x_{n}, y_{n}\right)=$ 0 . Then $\lim _{n \rightarrow \infty}\left\|x_{n}-y_{n}\right\|=0$.

Let $E$ be a reflexive, strictly convex, and smooth Banach space. The duality mapping $J^{*}$ from $E^{*}$ onto $E^{* * *}=E$ coincides with the inverse of the duality mapping $J$ from $E$ onto $E^{*}$, that is, $J^{*}=J^{-1}$. We make use the following mapping $V: E \times E^{*} \rightarrow \mathbb{R}$ studied in Alber [19]:

$$
V\left(x, x^{*}\right)=\|x\|^{2}-2\left\langle x, x^{*}\right\rangle+\left\|x^{*}\right\|^{2}
$$

for all $x \in E$ and $x^{*} \in E^{*}$. Obviously, $V\left(x, x^{*}\right)=\varphi\left(x, J^{-1}\left(x^{*}\right)\right)$ for all $x \in E$ and $x^{*} \in E^{*}$. We know the following lemma.

Lemma 2.5 [20]. Let $E$ be a reflexive, strictly convex, and smooth Banach space, and let $V$ as in (2.2). Then

$$
V\left(x, x^{*}\right)+2\left\langle J^{-1}\left(x^{*}\right)-x, y^{*}\right\rangle \leq V\left(x, x^{*}+y^{*}\right),
$$

for all $x \in E$ and $x^{*}, y^{*} \in E^{*}$.

Lemma 2.6 [21]. Assume that $\left\{\alpha_{n}\right\}$ is a sequence of nonnegative real numbers such that

$$
\alpha_{n+1} \leq\left(1-\gamma_{n}\right) \alpha_{n}+\gamma_{n} \delta_{n}
$$

where $\left\{\gamma_{n}\right\}$ is a sequence in $(0,1)$ and $\left\{\delta_{n}\right\}$ is a sequence such that

(a) $\lim _{n \rightarrow \infty} \gamma_{n}=0, \sum_{n=1}^{\infty} \gamma_{n}=\infty$;

(b) $\lim \sup _{n \rightarrow \infty} \leq 0$.

Then $\lim _{n \rightarrow \infty} \alpha_{n}=0$.

Lemma 2.7 [22]. Let $\left\{\alpha_{n}\right\}$ be a sequence of real numbers such that there exists a subsequence $\left\{n_{i}\right\}$ of $\{n\}$ such that $\alpha_{n_{i}}<\alpha_{n_{i}+1}$ for all $i \in \mathbb{N}$. Then there exists a nondecreasing sequence $\left\{m_{k}\right\} \subset \mathbb{N}$ such that $m_{k} \rightarrow \infty$ and the following properties are satisfied for all (sufficiently large) numbers $k \in \mathbb{N}$ :

$$
\alpha_{m_{k}} \leq \alpha_{m_{k}+1} \text { and } \alpha_{k} \leq \alpha_{m_{k}+1} \text {. }
$$


In fact, $m_{k}=\max \left\{j \leq k: \alpha_{j}<\alpha_{j+1}\right\}$.

\section{Main results}

Lemma 3.1 Let $E$ be a strictly convex and smooth Banach space, and $D$ a nonempty closed subset of $E$. Suppose $T: D \rightarrow N(D)$ is a quasi- $\varphi$-nonexpansive multi-valued mapping. Then $F(T)$ is closed and convex.

Proof. First, we show $F(T)$ is closed. Let $\left\{x_{n}\right\}$ be a sequence in $F(T)$ such that $x_{n} \rightarrow$ $x^{*}$. Since $T$ is quasi- $\varphi$-nonexpansive, we have

$$
\phi\left(x_{n}, z\right) \leq \phi\left(x_{n}, x^{*}\right)
$$

for all $z \in T\left(x^{*}\right)$ and for all $n \in \mathbb{N}$. Therefore,

$$
\begin{aligned}
\phi\left(x^{*}, z\right) & =\lim _{n \rightarrow \infty} \phi\left(x_{n}, z\right) \\
& \leq \lim _{n \rightarrow \infty} \phi\left(x_{n}, x^{*}\right) \\
& =\phi\left(x^{*}, x^{*}\right) \\
& =0 .
\end{aligned}
$$

By Lemma 2.1(c), we obtain $x^{*}=z$. Hence, $T\left(x^{*}\right)=\left\{x^{*}\right\}$. So, we have $x^{*} \in F(T)$. Next, we show $F(T)$ is convex. Let $x, y \in F(T)$ and $t \in(0,1)$, put $p=t x+(1-t) y$. We show $p \in F(T)$. Let $w \in F(p)$, we have

$$
\begin{aligned}
\phi(p, w) & =\|p\|^{2}-2\langle p, J w\rangle+\|w\|^{2} \\
& =\|p\|^{2}-2\langle t x+(1-t) y, J w\rangle+\|w\|^{2} \\
& =\|p\|^{2}-2 t\langle x, J w\rangle-2(1-t)\langle y, J w\rangle+\|w\|^{2} \\
& =\|p\|^{2}+t \phi(x, w)+(1-t) \phi(y, p)-t\|x\|^{2}-t(1-t)\|p\|^{2} \\
& =\|p\|^{2}-2\langle t x+(1-t) y, J p\rangle+\|p\|^{2} \\
& =\|p\|^{2}-2\langle p, J p\rangle+\|p\|^{2} \\
& =0 .
\end{aligned}
$$

By Lemma 2.1(c), we obtain $p=w$. Hence, $T(p)=\{p\}$. So, we have $p \in F(T)$. Therefore, $F(T)$ is convex.

Lemma 3.2. Let $D$ be a nonempty closed convex subset of a reflexive, strictly convex, and smooth Banach space $E$ and $T: D \rightarrow N(D)$ be a relatively nonexpansive multivalued mapping. If $\left\{x_{n}\right\}$ is a bounded sequence such that $\lim _{n \rightarrow \infty} d\left(x_{n}, T x_{n}\right)$ and $x^{*}=\Pi_{F}$ $(T)^{x}$, then

$$
\lim _{n \rightarrow \infty} \sup \left\langle x_{n}-x^{*}, J x-J x^{*}\right\rangle \leq 0 .
$$

Proof. From (S3) of the mapping $T$, we choose a subsequence $\left\{x_{n_{i}}\right\}$ of $\left\{x_{n}\right\}$ such that $x_{n_{i}} \rightarrow y \in F(T)$ and

$$
\lim _{n \rightarrow \infty} \sup \left\langle x_{n}-x^{*}, J x-J x^{*}\right\rangle=\lim _{i \rightarrow \infty}\left\langle x_{n_{i}}-x^{*}, J x-J x^{*}\right\rangle .
$$

By Lemma 2.1(b), we immediately obtain that

$$
\lim _{n \rightarrow \infty} \sup \left\langle x_{n}-x^{*}, J x-J x^{*}\right\rangle=\left\langle y-x^{*}, J x-J x^{*}\right\rangle \leq 0 .
$$


Lemma 3.3. Let $D$ be a nonempty closed convex subset of a reflexive, strictly convex, and smooth Banach space $E$ and $T: D \rightarrow N(D)$ be a relatively nonexpansive multivalued mapping. Let $\left\{x_{n}\right\}$ be a sequence in $D$ defined as follows: $u \in E, x_{1} \in D$ and

$$
x_{n+1}=\prod_{D} J^{-1}\left(\alpha_{n} J u+\left(1-\alpha_{n}\right)\left(\beta_{n} J x_{n}+\left(1-\beta_{n}\right) J w_{n}\right)\right),
$$

where $w_{n} \in T x_{n}$ for all $n \in \mathbb{N},\left\{\alpha_{n}\right\},\left\{\beta_{n}\right\}$ are sequences in $[0,1]$. Then $\left\{x_{n}\right\}$ is bounded.

Proof. Let $p \in F(T)$ and $y_{n}=J^{-1}\left(\beta_{n} J x_{n}+\left(1-\beta_{n}\right) J w_{n}\right)$ for all $n \in \mathbb{N}$. Then

$$
x_{n+1} \equiv \prod_{D} J^{-1}\left(\alpha_{n} J u+\left(1-\alpha_{n}\right) J y_{n}\right)
$$

for all $n \in \mathbb{N}$. By using (1.4), we have

$$
\begin{aligned}
\phi\left(p, y_{n}\right) & =\phi\left(p, J^{-1}\left(\beta_{n} J x_{n}+\left(1-\beta_{n}\right) J w_{n}\right)\right) \\
& \leq \beta_{n} \phi\left(p, x_{n}\right)+\left(1-\beta_{n}\right) \phi\left(p, w_{n}\right) \\
& \leq \beta_{n} \phi\left(p, x_{n}\right)+\left(1-\beta_{n}\right) \phi\left(p, x_{n}\right) \\
& =\phi\left(p, x_{n}\right)
\end{aligned}
$$

and

$$
\begin{aligned}
\phi\left(p, x_{n+1}\right) & =\phi\left(p, \prod_{D} J^{-1}\left(\alpha_{n} J u+\left(1-\alpha_{n}\right) J y_{n}\right)\right) \\
& \leq \phi\left(p, J^{-1}\left(\alpha_{n} J u+\left(1-\alpha_{n}\right) J y_{n}\right)\right) \\
& \leq \alpha_{n} \phi(p, u)+\left(1-\alpha_{n}\right) \phi\left(p, y_{n}\right) \\
& \leq \alpha_{n} \phi(p, u)+\left(1-\alpha_{n}\right) \phi\left(p, x_{n}\right) \\
& \left.\leq \max \left\{\phi(p, u), \phi\left(p, x_{n}\right)\right\}\right) \\
& \leq \cdots \\
& \left.\leq \max \left\{\phi(p, u), \phi\left(p, x_{1}\right)\right\}\right) .
\end{aligned}
$$

This implies that $\left\{x_{n}\right\}$ is bounded.

Theorem 3.4 Let $D$ be a nonempty closed convex subset of a uniformly convex and uniformly smooth Banach space $E$ and $T: D \rightarrow N(D)$ be a relatively nonexpansive multivalued mapping. Let $\left\{\alpha_{n}\right\}$ and $\left\{\beta_{n}\right\}$ be sequences in $(0,1)$ satisfying

(C1) $\lim _{n \rightarrow \infty}, \alpha_{n}=0$;

(C2) $\sum_{n=1}^{\infty} \alpha_{n}=\infty$;

(C3) $\lim \inf _{n \rightarrow \infty} \beta_{n}\left(1-\beta_{n}\right)>0$.

Then $\left\{x_{n}\right\}$ defined by (3.1) converges strongly to $\Pi_{F(T)} u$, where $\Pi_{F(T)}$ is the generalized projection from $E$ onto $F(T)$.

Proof. By Lemma 3.1, $F(T)$ is closed and convex. So, we can define the generalized projection $\Pi_{F(T)}$ onto $F(T)$. Putting $u^{*}=\prod_{F(T)} u$, by Lemma 3.3 we know that $\left\{x_{n}\right\}$ is bounded and hence, $\left\{w_{n}\right\}$ is bounded. Let $g:[0,2 r] \rightarrow[0, \infty)$ be a function satisfying the properties of Lemma 2.3, where $r=\sup \left\{\|u\|,\left\|x_{n}\right\|,\left\|w_{n}\right\|: n \in \mathbb{N}\right\}$. Put

$$
y_{n} \equiv J^{-1}\left(\beta_{n} J u+\left(1-\beta_{n}\right) J w_{n}\right)
$$


Then

$$
\begin{aligned}
\phi\left(u^{*}, y_{n}\right)= & \phi\left(u^{*}, J^{-1}\left(\beta_{n} J x_{n}+\left(1-\beta_{n}\right) J w_{n}\right)\right) \\
= & \left\|u^{*}\right\|^{2}-2\left\langle u^{*}, \beta_{n} J x_{n}+\left(1-\beta_{n}\right) J w_{n}\right\rangle+\left\|\beta_{n} J x_{n}+\left(1-\beta_{n}\right) J w_{n}\right\|^{2} \\
\leq & \left\|u^{*}\right\|^{2}-2 \beta_{n}\left\langle u^{*}, J x_{n}\right\rangle-2\left(1-\beta_{n}\right)\left\langle u^{*}, J w_{n}\right\rangle+\beta_{n}\left\|x_{n}\right\|^{2}+\left(1-\beta_{n}\right)\left\|w_{n}\right\|^{2} \\
& -\beta_{n}\left(1-\beta_{n}\right) g\left(\left\|J x_{n}-J w_{n}\right\|\right) \\
= & \phi\left(u^{*}, x_{n}\right)-\beta_{n}\left(1-\beta_{n}\right) g\left(\left\|J x_{n}-J w_{n}\right\|\right)
\end{aligned}
$$

and

$$
\begin{aligned}
\phi\left(u^{*}, x_{n+1}\right) & =\phi\left(u^{*}, \prod_{D} J^{-1}\left(\alpha_{n} J u+\left(1-\alpha_{n}\right) J y_{n}\right)\right) \\
& \leq \phi\left(u^{*}, J^{-1}\left(\alpha_{n} J u+\left(1-\alpha_{n}\right) J y_{n}\right)\right) \\
& \leq \alpha_{n} \phi\left(u^{*}, u\right)+\left(1-\alpha_{n}\right) \phi\left(u^{*}, y_{n}\right) \\
& \leq \alpha_{n} \phi\left(u^{*}, u\right)+\left(1-\alpha_{n}\right)\left(\phi\left(u^{*}, x_{n}\right)-\beta_{n}\left(1-\beta_{n}\right) g\left(\left\|J x_{n}-J w_{n}\right\|\right)\right) .
\end{aligned}
$$

for all $n \in \mathbb{N}$. Put

$$
M=\sup \left\{\left|\phi\left(u^{*}, u\right)-\phi\left(u^{*}, x_{n}\right)\right|+\beta_{n}\left(1-\beta_{n}\right) g\left(|| J x_{n}-J w_{n}\right): n \in \mathbb{N}\right\}
$$

It follows from (3.3) that

$$
\beta_{n}\left(1-\beta_{n}\right) g\left(\left\|J x_{n}-J w_{n}\right\|\right) \leq \phi\left(u^{*}, x_{n}\right)-\phi\left(u^{*}, x_{n+1}\right)+\alpha_{n} M .
$$

Let $z_{n} \equiv J^{-1}\left(\alpha_{n} J u+\left(1-\alpha_{n}\right) J y_{n}\right)$. Then $x_{n+1}=\prod_{C^{z} n}$ for all $n \in \mathbb{N}$. It follows from (2.3) and (3.2) that

$$
\begin{aligned}
\phi & \left(u^{*}, x_{n+1}\right) \\
& \leq \phi\left(u^{*}, J^{-1}\left(\alpha_{n} J u+\left(1-\alpha_{n}\right) J y_{n}\right)\right)=V\left(u^{*}, \alpha_{n} J u+\left(1-\alpha_{n}\right) J y_{n}\right) \\
& \leq V\left(u^{*}, \alpha_{n} J u+\left(1-\alpha_{n}\right) J y_{n}-\alpha_{n}\left(J u-J u^{*}\right)\right)-2\left\langle J^{-1}\left(\alpha_{n} J u+\left(1-\alpha_{n}\right) J y_{n}\right)-u^{*},-\alpha_{n}\left(J u-J u^{*}\right)\right\rangle \\
& =V\left(u^{*}, \alpha_{n} J u^{*}+\left(1-\alpha_{n}\right) J y_{n}\right)+2 \alpha_{n}\left\langle z_{n}-u^{*}, J u-J u^{*}\right\rangle \\
& =\phi\left(u^{*}, J^{-1}\left(\alpha_{n} J u^{*}+\left(1-\alpha_{n}\right) J y_{n}\right)\right)+2 \alpha_{n}\left\langle z_{n}-u^{*}, J u-J u^{*}\right\rangle \\
& =\left\|u^{*}\right\|^{2}-2\left\langle u^{*}, \alpha_{n} J u^{*}+\left(1-\alpha_{n}\right) J y_{n}\right\rangle+\left\|\alpha_{n} J u^{*}+\left(1-\alpha_{n}\right) J y_{n}\right\|^{2}+2 \alpha_{n}\left\langle z_{n}-u^{*}, J u-J u^{*}\right\rangle \\
& \leq\left\|u^{*}\right\|^{2}-2 \alpha_{n}\left\langle u^{*}, J u^{*}\right\rangle-2\left(1-\alpha_{n}\right)\left\langle u^{*}, J y_{n}\right\rangle+\alpha_{n}\left\|u^{*}\right\|^{2}+\left(1-\alpha_{n}\right)\left\|y_{n}\right\|^{2}+2 \alpha_{n}\left\langle z_{n}-u^{*}, J u-J u^{*}\right\rangle \\
& =\alpha_{n} \phi\left(u, u^{*}\right)+\left(1-\alpha_{n}\right) \phi\left(u^{*}, y_{n}\right)+2 \alpha_{n}\left\langle z_{n}-u^{*}, J u-J u^{*}\right\rangle \\
& \leq\left(1-\alpha_{n}\right) \phi\left(u^{*}, x_{n}\right)+2 \alpha_{n}\left\langle z_{n}-u^{*}, J u-J u^{*}\right\rangle .
\end{aligned}
$$

The rest of proof will be divided into two parts:

Case (1). Suppose that there exists $n_{0} \in \mathbb{N}$ such that $\left\{\phi\left(u^{*}, x_{n}\right)\right\}_{n=n_{0}}^{\infty}$ is nonincreasing. In this situation, $\left\{\varphi\left(u^{*}, x_{n}\right)\right\}$ is then convergent. Then $\lim _{n \rightarrow \infty}\left(\varphi\left(u^{*}, x_{n}\right)-\varphi\left(u^{*}, x_{n+1}\right)\right)=$ 0 . This together with (C1), (C3), and (3.4), we obtain

$$
\lim _{n \rightarrow \infty} g\left(\left\|J x_{n}-J w_{n}\right\|\right)=0 .
$$

Therefore,

$$
\lim _{n \rightarrow \infty}\left\|J x_{n}-J w_{n}\right\|=0 .
$$

Since $J^{-1}$ is uniformly norm-to-norm continuous on every bounded subset of $E$, we have

$$
\lim _{n \rightarrow \infty}\left\|x_{n}-w_{n}\right\|=0
$$


Since $d\left(x_{n}, T x_{n}\right) \leq\left\|x_{n}-w_{n}\right\|$, we obtain

$$
\lim _{n \rightarrow \infty} d\left(x_{n}, T x_{n}\right)=0
$$

Then,

$$
\begin{aligned}
\phi\left(w_{n}, y_{n}\right) & =\phi\left(w_{n} J^{-1}\left(\beta_{n} J x_{n}+\left(1-\beta_{n}\right) J w_{n}\right)\right) \\
& \leq \beta_{n} \phi\left(w_{n}, x_{n}\right)+\left(1-\beta_{n}\right) \phi\left(w_{n}, w_{n}\right) \\
& =\beta_{n} \phi\left(w_{n}, x_{n}\right) \rightarrow 0 .
\end{aligned}
$$

and

$$
\phi\left(y_{n}, z_{n}\right) \leq \alpha_{n} \phi\left(y_{n}, u\right)+\left(1-\alpha_{n}\right) \phi\left(y_{n}, y_{n}\right)=\alpha_{n} \phi\left(y_{n}, u\right) \rightarrow 0 .
$$

From (3.8), (3.9) and Lemma 2.3, we have

$$
\lim _{n \rightarrow \infty}\left\|w_{n}-y_{n}\right\|=0
$$

and

$$
\lim _{n \rightarrow \infty}\left\|y_{n}-z_{n}\right\|=0
$$

This together with (3.6) gives

$$
\lim _{n \rightarrow \infty}\left\|x_{n}-z_{n}\right\|=0
$$

From (3.7), (3.10) and invoking Lemma 3.2, we have

$$
\lim _{n \rightarrow \infty}\left\langle z_{n}-u^{*}, J u-J u^{*}\right\rangle=\lim _{n \rightarrow \infty}\left\langle x_{n}-u^{*}, J u-J u^{*}\right\rangle \leq 0
$$

Hence the conclusion follows by Lemma 2.5.

Case (2). Suppose that there exists a subsequence $\left\{n_{i}\right\}$ of $\{n\}$ such that

$$
\phi\left(u^{*}, x_{n_{i}}\right)<\phi\left(u^{*}, x_{n_{i}+1}\right)
$$

for all $i \in \mathbb{N}$. Then, by Lemma 2.7, there exists a nondecreasing sequence $\left\{m_{k}\right\} \subset \mathbb{N}$, $m_{k} \rightarrow \infty$ such that

$$
\phi\left(u^{*}, x_{m_{k}}\right) \leq \phi\left(u^{*}, x_{m_{k}+1}\right) \text { and } \phi\left(u^{*}, x_{k}\right) \leq \phi\left(u^{*}, x_{m_{k}+1}\right)
$$

for all $k \in \mathbb{N}$. This together with (3.4) gives

$$
\beta_{m_{k}}\left(1-\beta_{m_{k}}\right) g\left(\left\|J x_{m_{k}}-J w_{m_{k}}\right\|\right) \leq \phi\left(u^{*}, x_{m_{k}}\right)-\phi\left(u^{*}, x_{m_{k+1}}\right)+\alpha_{m_{k}} M \leq \alpha_{m_{k}} M
$$

for all $k \in N$. Then, by conditions (C1) and (C3)

$$
\lim _{k \rightarrow \infty} g\left(\left\|J x_{m_{k}}-J w_{m_{k}}\right\|\right)=0
$$

By the same argument as Case (1), we get

$$
\lim _{k \rightarrow \infty} \sup \left\langle z_{m_{k}}-u^{*}, J u-J u^{*}\right\rangle \leq 0 .
$$

From (3.5), we have

$$
\phi\left(u^{*}, x_{m_{k}+1}\right) \leq\left(1-\alpha_{m_{k}}\right) \phi\left(u^{*}, x_{m_{k}}\right)+2 \alpha_{m_{k}}\left\langle z_{m_{k}}-u^{*}, J u-J u^{*}\right\rangle
$$


Since $\phi\left(u^{*}, x_{m_{k}}\right) \leq \phi\left(u^{*}, x_{m_{k}+1}\right)$, we have

$$
\alpha_{m_{k}} \phi\left(u^{*}, x_{m_{k}}\right) \leq \phi\left(u^{*}, x_{m_{k}}\right)-\phi\left(u^{*}, x_{m_{k}+1}\right)+2 \alpha_{m_{k}}\left|z_{m_{k}}-u^{*}, J u-J u^{*}\right\rangle \leq 2 \alpha_{m_{k}}\left|z_{m_{k}}-u^{*}, J u-J u^{*}\right\rangle
$$

In particular, since $\alpha_{m_{k}}>0$, we get

$$
\phi\left(u^{*}, x_{m_{k}}\right) \leq 2\left\langle z_{m_{k}}-u^{*}, J u-J u^{*}\right\rangle
$$

It follows from (3.11) that $\lim _{k \rightarrow \infty} \phi\left(u^{*}, x_{m_{k}}\right)=0$. This together with (3.12) gives

$$
\lim _{k \rightarrow \infty} \phi\left(u^{*}, x_{m_{k}+1}\right)=0
$$

But $\phi\left(u^{*}, x_{k}\right) \leq \phi\left(u^{*}, x_{m_{k}+1}\right)$ for all $k \in \mathbb{N}$. We conclude that $x_{k} \rightarrow u^{*}$.

This implies that $\lim _{n \rightarrow \infty} x_{n}=u^{*}$ and the proof is finished.

Letting $\beta_{n}=\beta$ gives the following result.

Corollary 3.5. Let $D$ be a nonempty closed convex subset of a uniformly convex and uniformly smooth Banach space $E$ and $T: D \rightarrow N(D)$ be a relatively nonexpansive multivalued mapping. Let $\left\{x_{n}\right\}$ be a sequence in $D$ defined as follows: $u \in E, x_{1} \in D$ and

$$
x_{n+1}=\prod_{D} J^{-1}\left(\alpha_{n} J u+\left(1-\alpha_{n}\right)\left(\beta J x_{n}+(1-\beta) J w_{n}\right)\right),
$$

where $w_{n} \in T x_{n}$ for all $n \in \mathbb{N},\left\{\alpha_{n}\right\}$ is a sequence in $[0,1]$ satisfying condition (C1) and $(\mathrm{C} 2)$, and $\beta \in(0,1)$. Then $\left\{x_{n}\right\}$ converges strongly to $\prod_{F(T)} u$.

\section{Application to zero point problem of maximal monotone mappings}

Let $E$ be a smooth, strictly convex, and reflexive Banach space. An operator $A: E \rightarrow$ $2^{E^{*}}$ is said to be monotone, if $\left\langle x-y, x^{*}-y^{*}\right\rangle \geq 0$ whenever $x, y \in E, x^{*} \in A x, y^{*} \in A y$. We denote the zero point set $\{x \in E: 0 \in A x\}$ of $A$ by $A^{-1} 0$. A monotone operator $A$ is said to be maximal, if its graph $G(A):=\{(x, y): y \in A x\}$ is not properly contained in the graph of any other monotone operator. If $A$ is maximal monotone, then $A^{-1} 0$ is closed and convex. Let $A$ be a maximal monotone operator, then for each $r>0$ and $x$ $\in E$, there exists a unique $x_{r} \in D(A)$ such that $J(x) \in J\left(x_{r}\right)+r A\left(x_{r}\right)$ (see, for example, [19]). We define the resolvent of $A$ by $J_{r} x=x_{r}$. In other words $J_{r}=(J+r A)_{-1}{ }^{1} J, \forall r>0$. We know that $J_{r}$ is a single-valued relatively nonexpansive mapping and $A^{-1} 0=F\left(J_{r}\right), \forall r$ $>0$, where $F\left(J_{r}\right)$ is the set of fixed points of $J_{r}$.

We have the following

Theorem 4.1 Let $E$, $\left\{\alpha_{n}\right\}$, and $\left\{\beta_{n}\right\}$ be the same as in Theorem 3.4. Let $A: E \rightarrow 2^{E^{n}}$ be a maximal monotone operator and $J_{r}=(J+r A)^{-1} J$ for all $r>0$ such that $A^{-1} 0 \neq \emptyset$. Let $\left\{x_{n}\right\}$ be the sequence generated by

$$
x_{n+1}=J^{-1}\left[\alpha_{n} J x_{1}+\left(1-\alpha_{n}\right)\left(\beta_{n} J x_{n}+\left(1-\beta_{n}\right) J J_{r_{n}} x_{n}\right)\right],
$$

then $\left\{x_{n}\right\}$ converges strongly to $\Pi_{A}-1_{0} x_{1}$.

Proof. In Theorem 3.4 taking $D=E, T=J_{r}, r>0$, then $T: E \rightarrow E$ is a single-valued relatively nonexpansive mapping and $A^{-1} 0=F(T)=F\left(J_{r}\right), \forall r>0$ is a nonempty closed convex subset of $E$. Therefore all the conditions in Theorem 3.4 are satisfied. The conclusion of Theorem 4.1 can be obtained from Theorem 3.4 immediately. 


\section{Author details}

${ }^{1}$ Department of Mathematics, Yibin University, Yibin, Sichuan 644007, P. R. China ${ }^{2}$ College of Statistics and Mathematics, Yunnan University of Finance and Economics, Kunming, Yunnan 650221, China

\section{Authors' contributions}

All the authors contributed equally to the writing of the present article. And they also read and approved the final manuscript.

\section{Competing interests}

The authors declare that they have no competing interests.

Received: 29 January 2012 Accepted: 29 March 2012 Published: 29 March 2012

\section{References}

1. Cioranescu, I: Geometry of Banach Spaces, Duality Mappings and Nonlinear Problems. Kluwer Academic Press, Dordrecht (1990)

2. Alber, YI: Metric and Generalized Projection Operators in Banach Spaces. pp. 15-50. Marcel Dekker, New York (1996)

3. Matsushita, S, Takahashi, W: Weak and strong convergence theorems for relatively nonexpansive mappings in a Banach spaces. Fixed point Theory Appl. 2004, 37-47 (2004)

4. Matsushita, S, Takahashi, W: An iterative algorithm for relatively nonexpansive mappings by hybrid method and applications. Proceedings of the Third International Conference on Nonlinear Analysis and Convex Analysis. 305-313 (2004)

5. Matsushita, S, Takahashi, W: A strong convergence theorem for relatively nonexpansive mappings in a Banach spaces. J Approx Theory. 134, 257-266 (2005). doi:10.1016/j.jat.2005.02.007

6. Nilsrakoo, W, Saejung, S: Strong convergence to common fixed points of countable relatively quasi-nonexpansive mappings. Fixed Point Theory and Applications2008, 19. Article ID 312454

7. Nilsrakoo, W, Saejung, S: Strong convergence theorems by Halpern-Mann iterations for relatively nonexpansive mappings in Banach spaces. Appl Math Comput. 217(14):6577-6584 (2011). doi:10.1016/j.amc.2011.01.040

8. Jung, JS: Strong convergence theorems for multivalued nonexpansive nonself-mappings in Banach spaces. Nonlinear Anal. 66, 2345-2354 (2007). doi:10.1016/j.na.2006.03.023

9. Shahzad, N, Zegeye, H: Strong convergence results for nonself multimaps in Banach spaces. Proc Am Soc. 136, 539-548 (2008)

10. Shahzad, N, Zegeye, H: On Mann and Ishikawa iteration schems for multi-valued maps in Banach spaces. Nonlinear Anal. 71, 838-844 (2009). doi:10.1016/j.na.2008.10.112

11. Song, Y, Wang, $\mathrm{H}$ : Convergence of iterative algorithms for multivalued mappings in Banach spaces. Nonlinear Anal. 70, 1547-1556 (2009). doi:10.1016/j.na.2008.02.034

12. Cho, YJ, Qin, X, Kang, SM: Strong convergence of the modified Halpern-type iteration algorithms in Banach spaces. An St Univ Ovidius Constanta Ser Mat. 17, 51-68 (2009)

13. Qin, X, Cho, YJ, Kang, SM, Zhou, H: Convergence of a modified Halpern-type iteration algorithm for quasi- $\mathbb{-}$ nonexpansive mappings. Appl Math Lett. 22, 1051-1055 (2009). doi:10.1016/j.aml.2009.01.015

14. Song, Y, Cho, YJ: Some notes on Ishikawa iteration for multi-valued mappings. Bull Korean Math Soc. 48, 575-584 (2011). doi:10.4134/BKMS.2011.48.3.575

15. Yao, Y, Cho, YJ: A strong convergence of a modified Krasnoselskii-Mann method for non-expansive mappings in Hilbert spaces. Math Model Anal. 15, 265-274 (2010). doi:10.3846/1392-6292.2010.15.265-274

16. Alber, YI: Metric and Generalized Projection Operators in Banach Spaces. pp. 15-50. Marcel Dekker, New York (1996)

17. Kamimura, S, Takahashi, W: Strong convergence of a proximal-type algorithm in a Banach space. SIAM J Optim. 13(3):938-945 (2002). doi:10.1137/S105262340139611X

18. Chang, SS, Kim, JK, Wang, XR: Modified Block Iterative Algorithm for Solving Convex feasibility Problems in Banach spaces. J Inequal Appl 2010, 14 (2010). Article ID 869684

19. Alber, YI: Metric and generalized projection operators in Banach spaces:properties and applications. In Theory and Applications of Nonlinear operators Of Accretive And Monotone Type, Lecture Notes in Pure and Applied Mathematics, vol. 178, pp. 15-50.Dekker, New York (1996)

20. Kohsaka, F, Takahashi, W: Strong convergence of an iterative sequence for maximal monotone operators in a Banach spaces. Abstr Appl Anal. 2004, 239-249 (2004). doi:10.1155/S1085337504309036

21. $\mathrm{Xu}, \mathrm{HK}$ : Another control condition in an iterative method for nonexpansive mappings. Bull Austral Math Soc. 65 , 109-113 (2002). doi:10.1017/S0004972700020116

22. Mainge, PE: Strong convergence of projected subgradient methods for nonsmooth and nonstrictly convex minimization. Jset-Valued Anal. 16, 899-912 (2008). doi:10.1007/s11228-008-0102-z

doi:10.1186/1029-242X-2012-73

Cite this article as: Zhu et al:: Strong convergence theorems by Halpern-Mann iterations for multi-valued relatively nonexpansive mappings in Banach spaces with applications. Journal of Inequalities and Applications 2012 2012:73. 